\title{
Exposure assessment of chemicals from packaging materials in foods: a review
}

\author{
Maria de Fátima Poças* and Timothy Hogg
}

\author{
Packaging Department, Biotechnology College, \\ Portuguese Catholic University, Rua Dr. António \\ Bernardino de Almeida, 4200-072 Porto, Portugal \\ (Tel.: + 351 225580086; fax: + 351 225580111; \\ e-mail: mfpocas@esb.ucp.pt)
}

It is recognised that chemicals from packaging and other foodcontact materials can migrate into the food itself and thus be ingested by the consumer. The monitoring of this migration has become an integral part of ensuring food safety. This article reviews the current knowledge on the food safety hazards associated with packaging materials together with the methodologies used in the assessment of consumer exposure to these hazards. Special attention is given to the most promising approaches for exposure assessment and to the technical and other barriers which need addressing.

\section{Introduction}

A variety of chemicals may enter our food supply, by means of intentional or unintentional addition, at different stages of the food chain. These chemicals include food additives, pesticide residues, environmental contaminants, mycotoxins, flavouring substances and micronutrients. Packaging systems and other food-contact materials are also a source of chemicals in food products and beverages. Monitoring exposure to these chemicals has become an integral part of ensuring the safety of the food supply. Within the context of the risk analysis approach, and more specifically as an integral part of risk assessment procedures, the exercise known as exposure assessment is crucial in providing data to allow sound judgements concerning risks to human health. The exercise of obtaining these data is part of the process of revealing sources of contamination and assessing the effectiveness of strategies for minimizing the risk from chemical contamination in the food supply (Lambe, 2002).

Human exposure to chemicals from packaging and other materials in contact with food may occur as a result of migration from the packaging materials into foodstuffs.
The extent of this migration and the specific toxicity of the substance(s) in question are the two main factors which define the human health risk which a packaging material represents. In the context of a formal risk assessment for a particular health hazard in a particular packaging material, the key characteristics that need to be considered are (i) exposure assessment - the levels of the specific hazard to which a population is exposed via this route and the production factors which influence these levels and (ii) hazard characterisation - the range of pathologies which this agent can provoke at various levels of exposure.

Exposure assessment is defined by the World Health Organisation (WHO) as the qualitative and/or quantitative evaluation of the likely intake of biological, chemical or physical agents via food as well as exposure from other sources if relevant (WHO, 1997). In exposure assessment of hazards from packaging systems, the use and intended technical effect of the substance must be described. In addition, descriptions are required of the analytical methods for the hazard's detection and/or quantification in foods and in the packaging itself and also of its migration behaviour. The hazard characterisation component includes toxicological studies and the effects of different levels on health, and a comprehensive profile of the substance, including its possible degradation products.

\section{Hazards of packaging materials in contact with foods}

The substances that may migrate and that may affect the safety of the food obviously depend on the nature of the packaging material. The constant introduction of novel packaging materials has increased the number of specific hazards to which humans are exposed via the migration from packaging into food (Arvanitoyannis \& Bosnea, 2004).

Synthetic polymers typically have high molecular weights (5000-1 million D) and therefore their biological availability is negligible. However, due to the use of lower molecular weight $(<1000 \mathrm{D})$ additives in these polymers as well as the presence of trace levels of unreacted monomers, there is 
a finite potential for human exposure to these lower molecular weight components (Leber, 2001). Substances that may migrate from plastic materials include monomers and starting substances, catalysts, solvents and additives. This latter class includes antioxidants, antistatics, antifogging agents, slip additives, plasticizers, heat stabilisers, dyes and pigments.

Paper and board are essentially composed of pulp from different vegetable sources and are most often employed in contact with dry foods. Additives used in this type of material include fillers, starch and derivatives, wet strength sizing agents, retention aids, biocides, fluorescent whitening agents and grease-proofing agents. Paper and board may also be coated with polymers as polyethylene or waxes. Recycled fibre is considered a major source of migrants (Aurela, Kulmala, \& Soderhjelm, 1999; Binderup et al., 2002; Sturaro, Rella, Parvoli, Ferrara, \& Tisato, 2006). This route of contamination is officially recognised in the Resolution RESAP (2002) 1 of the Council of Europe for paper and board in contact with foods, which lists DIPNs, benzophenone, partially hydrogenated terphenyls, solvents, phthalates, azo-colourants, primary aromatic amines and polycyclic aromatic hydrocarbons as being relevant (CoE, 2002; Escabasse \& Ottenio, 2002). Corrugated board is most often used as transport packaging system and thus not anticipated to come into direct contact with food. However, volatile substances in this type of material used as a secondary package may be transferred through the primary packaging into the food (Jickells, Poulin, Mountfort, \& Fernandez-Ocaña, 2005).

Metal cans are made of tin-plate (steel coated with tin), tin-free steel (steel coated with chromium and chromium oxides) or aluminium. Tin-plate is most used for food cans and aluminium for beverage cans. Most cans are internally coated with a polymeric layer, and thus the layer of food contact is not the metal but the lacquer. The substances of concern in can systems are therefore not only the metals involved, but also components migrating from the coatings, such as starting substances and their potential derivatives. Migrants from can coatings, namely phenolic resins, often contain only small amounts of monomers, oligomers and additives, but a large amount of other unknown or undescribed components (Grob, 2002).

Glass packaging has as its major components, silica, sodium and calcium oxides. These components are unlikely to have any significant effect on the safety of foods since they are natural constituents of many foods. Silica is also the major component of food-contact ceramics. Clays, another major raw material of ceramics, is composed of alumina, silica and water. Substances of concern may, however, originate from glazes and printing inks. Thus lead and cadmium are frequently controlled in such materials since they may be present as contaminants. The Food Standards Agency (UK) promoted a comprehensive overview of the potential for elemental migration from different glass types used in food-contact applications in a range of conditions of use (FSA, 2002).

As can been seen, there is a great variety of chemicals involved and an often complex mixture of migrants.
Additionally, the migrant species may not be the substance used in the production or conversion of the material, but an unknown reaction product. Non-intentionally added substances, like degradation products from additives or monomers and impurities, and substances originated in printing inks, adhesives, solvents, etc. may also migrate into the food under certain conditions (Arvanitoyannis \& Bosnea, 2004; Skjevrak et al., 2005). One of the current issues is the uncertainty in the identity and/or in the biological properties of the migrating substances (Castle, 2003). Non-identified and non-detected substances represent an uncharacterised contribution to the exposure of contaminants from food-contact materials (Skjevrak et al., 2005).

Unlike most food additives, the exposure to chemicals migrating from packaging materials is typically very low, in the range from less than $10 \mathrm{ppb}$ to $60 \mathrm{ppm}$ in the food. According to Paracelsus's maxim "the dose makes the poison", the EU follows a tiered approach for risk assessment of packaging migrants. Thus the European Food Safety Authority (EFSA) demands that the greater the extent of migration, the more toxicological information is required on the chemicals in question (Table 1). Toxicity test requirements depend upon exposure, structure-activity relationships and eventual environmental effects (Munro, Hlywka, \& Kennepohl, 2002). Once evaluated, substances are classified into a set of lists numbered from 0 to 9 according to their toxicity, the level of exposure and the toxicological data available (Table 2). Only substances classified into lists 0 to 4 will be permitted, being part of the EC's so-called "positive list".

\begin{tabular}{|c|c|}
\hline $\begin{array}{l}\text { Migration }<0.05 \mathrm{mg} / \mathrm{kg} \\
\text { (minimum dossier) }\end{array}$ & $\begin{array}{l}\text { A Mutagenicity studies in vitro } \\
\text { (test for gene mutations in } \\
\text { bacteria; test for induction of } \\
\text { gene mutation in mammalian } \\
\text { cells; test for induction of } \\
\text { chromosomal aberrations in } \\
\text { mammalian cells) }\end{array}$ \\
\hline $\begin{array}{l}0.05<\text { Migration }<5 \mathrm{mg} / \mathrm{kg} \\
\text { (intermediate dossier) }\end{array}$ & $\begin{array}{l}\Delta 3 \text { Mutagenicity studies in vitro } \\
\text { (as above) } \\
\text { A } 90 \text {-day oral toxicity studies } \\
\text { (in } 2 \text { species) } \\
\text { ब Data to demonstrate the } \\
\text { absence of potential for } \\
\text { accumulation in man }\end{array}$ \\
\hline $\begin{array}{l}5<\text { Migration }<60 \mathrm{mg} / \mathrm{kg} \\
\text { (full dossier) }\end{array}$ & 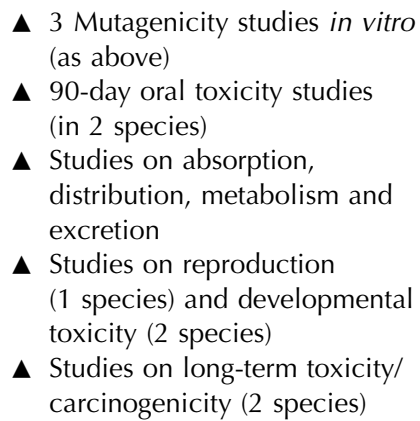 \\
\hline
\end{tabular}




\begin{tabular}{|c|c|}
\hline $\begin{array}{l}\text { SCF } \\
\text { list }\end{array}$ & Description \\
\hline 0 & $\begin{array}{l}\text { Substances allowed for plastics in contact, such as food } \\
\text { ingredients and certain substances from intermediate } \\
\text { metabolism of man, for which an ADI need not be } \\
\text { established }\end{array}$ \\
\hline 1 & $\begin{array}{l}\text { Substances, e.g. food additives, for which an ADI, t-ADI, } \\
\text { MTDI, PMTDI or PTWI has been established }\end{array}$ \\
\hline 2 & $\begin{array}{l}\text { Substances for which a TDI or a t-TDI has been } \\
\text { established }\end{array}$ \\
\hline 3 & $\begin{array}{l}\text { Substances for which an ADI or TDI could not be } \\
\text { established, but where the present use could be } \\
\text { accepted } \\
\text { - self-limiting substances because their organoleptic } \\
\text { properties or volatility } \\
\text { - substances with a very low migration without a TDI but } \\
\text { with a maximum level of use or a specific migration } \\
\text { limit stated }\end{array}$ \\
\hline 4 & $\begin{array}{l}\text { Substances (monomer and additives) for which a TDI } \\
\text { or a t-TDI has been established, but which could be used } \\
\text { if migration is non-detectable by an agreed sensitive } \\
\text { method, or if residues (monomers) in plastics are reduced } \\
\text { as much as possible }\end{array}$ \\
\hline 5 & Substances which should not be used \\
\hline 6 & $\begin{array}{l}\text { Substances for which there exist suspicion about toxicity } \\
\text { and for which data are lacking or are insufficient }\end{array}$ \\
\hline 7 & $\begin{array}{l}\text { Substances for which additional toxicological data are } \\
\text { required }\end{array}$ \\
\hline 8 & Substances with no, or inadequate data \\
\hline 9 & Substances which could not be evaluated \\
\hline W & $\begin{array}{l}\text { Waiting list of new substances (never approved at } \\
\text { national level) }\end{array}$ \\
\hline \multicolumn{2}{|c|}{$\begin{array}{l}\text { ADI, acceptable daily intake; t-ADI, temporary ADI; TDI, tolerable } \\
\text { daily intake; MTDI, maximum TDI; PMTDI, provisional maximum } \\
\text { TDI; PTWI, provisional tolerable weekly intake. }\end{array}$} \\
\hline
\end{tabular}

Once incorporated, a substance from a positive list can be used for any application, provided the migration limit set is not exceeded. Migration testing is performed according to EN 1186 standards which indicate the food simulants and contacting conditions to be used in the tests.

\section{Exposure assessments of substances of recent concern}

Plasticizers are widely distributed in the ecosystem and have been described as being among the most abundant man-made environmental pollutants. Humans are exposed to these compounds through ingestion, inhalation and dermal exposure for their whole lifetime (Latini, 2005). Diesters of phthalic acid (referred to often as phthalates) and other plasticizers have been the focus of several surveys and exposure assessments (Aurela et al., 1999; EFSA, 2004; Freire, Santana, \& Reyes, 2006; Grob et al., 2007).

Bisphenols and their derivatives with epoxy or chlorohydrin groups are known to be endocrine disruptors in humans as well as being potentially carcinogenic. Their release from can coatings/varnishes, polycarbonate (PC) bottles and sealants have been of considerable recent concern (Dionisi \& Oldring, 2002; Fankhauser-Noti \& Grob,
2004; Holmes, Hart, Northing, Oldring, \& Castle, 2005; Simoneau, Theobald, Wiltschko, \& Anklam, 1999; Thomson \& Grounds, 2005; Wong, Leo, \& Seah, 2005).

Metal lids used in glass jars may also be a source of potential contaminants: semicarbazide in baby food jars, resulting from degradation of azodicarbonamide used as blowing agent, and epoxidised soybean oil (ESBO) a plasticizer used in the plastisol gasket (Nestmann et al., 2005). EFSA recommended the decrease of the legal specific migration limit (SML) for ESBO, for infants food packaging applications, from 60 to $30 \mathrm{mg} / \mathrm{kg}$ of food or food simulant (Directive 2005/72).

Primary aromatic amines can be derived from the hydrolysis of aromatic isocyanates used in adhesives and from azo-dyes. They have been detected in kitchen utensils, particularly those made of black nylon, leading to a number of actions by the European Rapid Alert System for Food and Feed (Brede and Skjevrak, 2004; DFVF, 2004).

Other important studies have been devoted to the monomers used in plastic materials (Bradley, Boughtflower, Smith, Speck, \& Castle, 2005; Bradley, Speck, Read, \& Castle, 2004; FSA, 2003; Leber, 2001; Lickly, Breder, \& Rainey, 1995; Mutsuga, Tojima, Kawamura, \& Tanamoto, 2005). Although most studies have been devoted to organic molecules, work on mineral hydrocarbons (Castle, Kelly, \& Gilbert, 1993; Heimbach et al., 2002; MAFF, 2003; Tennant, 2004) and metallic elements (FSA, 2002; Leblanc et al., 2005; Ysart et al., 1999) have also been reported.

\section{Methodologies for exposure assessment}

The choice of method for carrying out an exposure assessment is influenced by the purpose of the exercise, the nature of the chemical, and the resources and data available (Lambe, 2002). When estimating chemical exposure, four basic guiding principles should be followed (Rees \& Tennant, 1993):

$>$ the estimate should be appropriate for the purpose,

$>$ the estimate should have an assessment of accuracy,

$>$ any underlying assumptions should be stated clearly and

$>$ critical groups of the population should be taken into account when these groups are disproportionally affected by the chemical.

The differences between food additives (direct) and substances migrating from packaging (referred to in a US context as "indirect additives") are such that they require different methodologies when assessing consumer exposure to them. When the substance in question is not a direct food chemical, such as food additive, natural toxin or pesticide residue, but a chemical migrating from the packaging system, additional information is needed on the nature and composition of the packaging materials, the types of packages used for certain foods (related to packaging usage factors) and data on migration levels of the substance in question. 
Exposure, in a dietary context, is defined as the amount of a certain substance that is consumed (Holmes et al., 2005) and is usually expressed as the amount of substance per mass of consumer body weight per day. The general model to describe the exposure to chemicals from food packaging can be represented as:

$$
\begin{aligned}
& \text { Exposure }(\mathrm{mg} / \text { person } / \text { day })=\text { Concentration }\left(\mathrm{mg} / \mathrm{kg}_{\text {food }}\right) \\
& \times \text { Food Consumption }\left(\mathrm{kg}_{\text {food }} / \text { person } / \text { day }\right)
\end{aligned}
$$

where Concentration represents the concentration of the chemical that contaminates the food. Food Consumption represents the intake of food packed in a certain type of packaging system that contains the migrating chemical.

Alternatively, exposure can be expressed in terms of the amount of packaging used which contains the chemical in question.

$$
\begin{aligned}
& \text { Exposure }(\mathrm{mg} / \text { person } / \text { day })=\text { Migration }\left(\mathrm{mg} / \mathrm{dm}^{2}\right) \\
& \times \text { Packaging Usage }\left(\mathrm{dm}^{2} / \text { person/day }\right)
\end{aligned}
$$

where Migration represents the amount of chemical migrating into the food. The migration level depends on several variables such as the packaging material itself, the chemical and physical nature of the food in contact, the initial concentration of the substance in the packaging material, time and temperature, and it also depends on the ratio of surface area of packaging material to the amount of food product.

The methodologies followed for assessing direct food chemicals, such as food additives, contaminants, natural toxins and residues of pesticides or veterinary drugs are widely reported (Kroes et al., 2002; Luetzow, 2003). These studies are normally based on either:

$>$ point estimates - that uses a single "best guess" estimate for each variable within a model (Vose, 2000), and

$>$ probabilistic analysis - that involves describing variables in terms of distributions to characterise their variability and/or uncertainty.

Point estimates are often used in a screening phase of exposure assessments with conservative estimates of variable and uncertain inputs to ensure "worst case" or upper-limit estimates of exposure. These analyses are usually quick and relatively inexpensive to execute and they can serve to identify potential exposures that are so low that more detailed analyses are not worthwhile. However, due to variability and uncertainty in the model input variables, deterministic pointestimates provide no indication of the magnitude of uncertainty surrounding the quantities estimated and lend no insight into the key sources of underlying uncertainty, although some insight can be provided with deterministic sensitivity analyses (Kroes et al., 2002).

The probabilistic approach uses distributions of values rather than single values estimated for food consumption (or packaging usage) and concentration (or migration), and the outputs are exposure distributions (Hart, Smith, Macarthur, \& Rose, 2003). It gives quantitative information about both the range and the likelihood of possible exposure values for a set of individuals, allowing for the characterisation of variability and uncertainty in model outputs. Additionally, this approach makes it possible to identify key sources of uncertainty and variability that can be the focus of future data collection, research, or model development efforts (Cullen \& Frey, 1999; Kroes et al., 2002).

The methods can follow a hierarchical and stepwise approach, proceeding from the level of more conservative assumptions and lower accuracy to the more refined estimates if the less exact results do not rule out the possibility of compliance with the food safety objective. The European Union proposed a tiered approach for monitoring food additive intakes (EU, no date). In assessing exposure to chemicals from packaging materials, a similar tiered approach for combining or integrating the food consumption data with the migration data may be applied. These approaches may range from making the assumptions of $100 \%$ migration, to more refined methods taking into account quantitative measures of migration into foods linked to survey data on intake of specific foods.

Human exposure to chemicals can alternatively be determined by measuring the concentration of the substance or its metabolites in body fluids. Biomarkers, such as urinary metabolites or hemoglobin adducts, that can give a more direct measure of exposure to a substance may be used either to assess that exposure or to validate and improve other indirect dietary exposure models such as probabilistic models (ILSI, 2002). This represents an unambiguous assessment and allows the quantification of the actual individual exposure of each subject to the substance, independently from the various possible routes of external exposure (Anderson, Castle, Scotter, Massey, \& Springall, 2001; Latini, 2005). However, this approach is very costly, more difficult to implement and also has analytical limitations. For biomarkers to be useful, the metabolite should be uniquely associated with the substance of interest, the relationship between dietary exposure and excretion should be established, any variation in excretion between individuals should be known and the possibility of other sources of the chemical in question (endogenous or exogenous) with contribution to that metabolite, should be accounted for (ILSI, 2002).

\section{Data collection for exposure assessments}

As shown in Eqs. (1) and (2), two types of data are required to estimate the exposure or intake of a chemical from packaging materials - concentration or migration data and food consumption or packaging usage data. This section briefly presents the techniques available for data collection.

\section{Migration data}

Migration data may be obtained from monitoring levels of chemicals in real food systems. There are major analytical difficulties with this approach due to the complexity of 
the food matrixes and to the chemical instability of some migrants. More commonly, migration data are obtained from migration experiments, carried out under controlled conditions of time and temperature of contact between the materials and a food simulant instead of the food itself. Such simulants include water, ethanol solutions, acetic acid solutions and olive oil (Directives EEC 85/572, EC 97/48). Recently, a diffusion model for estimation of the migration of components from plastic materials has been allowed for determining compliance with regulations (Directive 2002/ 72/EC).

\section{Packaging usage data}

Food consumption and packaging usage data are, unfortunately, rarely collected together, as most of the surveys are designed to gather information on energy, nutrients or certain residues and food contaminants or additives regardless of the packaging system the food was contained in. Thus, adequate information of packaging usage is not easily available. For assessing the exposure to packaging chemicals, it is necessary to know what type of food (chemical and physical nature) is packaged in what type of material, as this determines the presence and concentration of the chemical and influences the potential for migration into the type of food. For example, considering the consumption of mineral water, the chemicals migrating from polyethylene terephthalate (PET) bottles are certainly different from those migrating into the same mineral water packaged in PC bottles. On the other hand, if the migration from PET bottles is considered, the migration value of a certain substance will be different if we consider a soft drink (acid in nature) instead of a mineral water.

Another factor to be considered in linking packaging usage, food consumption and migration data is the ratio of surface area of the packaging to volume of food product. Mass transfer of the chemical is a surface area phenomena and the concentration achieved in the food or food simulant depends on its volume or mass. Therefore, the size and format of the packages are also very important. The European legislation system assumes that $1 \mathrm{~kg}$ of food is exposed to $6 \mathrm{dm}^{2}$, but the current trend to smaller portions and therefore smaller packages, points to the need for revising this assumed value of surface area to volume ratio (Grob et al., 2007).

Statistics on food packaging materials usage may be obtained from different complementary sources and processed to generate an overview. Such sources would certainly include industry sources and shelf audits along with information from food producers, packaging converters, raw material suppliers and trade associations. The packaging statistics are best collected already segmented into food type, pack size and packaging material. For each of these, the number of units of consumption, surface area, weight of packaging and coating thicknesses must be estimated (ILSI, 2002). There is a recognised need for more complete information on packaging systems used - type, amount and linkage to food consumption. An interesting development in this respect is the database developed in Ireland, concerning package-derived chemical exposure in children aged 5-12 years. The information was collected during a 7-day food intake survey of 594 children. The information included food intake data and the following data for packaging: type, contact layer identification, multilayer $(y / n)$, EU food category and migration conditions (Duffy, Hearty, Gilsenan, \& Gibney, 2006).

\section{Food consumption data}

Food consumption data are generally much more abundant and available. The method employed for collection is directly related to the purpose of the exposure assessment and with the accuracy of the model. Several methods can be used to estimate the intake of a food chemical and the choice will depend on what information is available and how accurate and detailed the estimate needs to be (Kroes et al., 2002).

Food consumption data may be collected at different levels:

national - food balance sheets or per capita estimates

> household - budget and consumption surveys, or

$>$ individual $-24 \mathrm{~h}$ recalls, questionnaires, dietary records, interviews.

When exposure in specific subgroups (e.g. children) is of interest, data on individual level are essential.

Since 1993, an effort has been made to create a cost-effective, European Databank based on food, socioeconomic and demographic data from nationally representative household budget surveys. This initiative, known as the DAFNE project - Data Food Networking, includes data from 44 household budget surveys from 8 EU Member States and Norway. The year and the procedures of data collection and storage, the methodological characteristics and other general information regarding the integrated datasets are presented in the Project Report. A database for intake of food additives, pesticide residues and nutrients was developed in the scope of the Monte Carlo project using more refined techniques for collecting information (Leclercq et al., 2003).

\section{Point estimates and screening approaches}

There are a number of factors that influence the choice of model for any given exposure assessment. A stepwise approach which takes into account the accuracy of the results is advised by the WHO. This approach progresses from initial screening methods, to more specific procedures that use actual data of concentration and consumption and, in some cases, the use of biomarkers or duplicate diet studies to provide even more accurate data. Screening methods are usually based on assumptions for both model variables (food consumption or packaging usage and migration) leading to a considerable overestimate of exposure. This estimate might permit a decision as to whether any further 
work, using more sophisticated models to provide results with a higher certainty, might be needed. If this initial screening indicates that there is no practical likelihood that consumers are exposed to levels exceeding the safety objectives, for example the tolerable daily intake (TDI, $\mathrm{mg} / \mathrm{kg} \mathrm{bw/day)}$ or the acceptable daily intake (ADI, mg/ $\mathrm{kg}$ bw/day), or if the intake is clearly below an agreed threshold of toxicological concern, it may be decided that no further refinement of the assessment is needed (FSA, 2003; Kroes et al., 2002).

The screening phase of exposure assessment is, very often, performed as point estimates since they are relatively simple and inexpensive to carry out. Point estimates consider a single value for consumption of a food (usually the mean population value) and a fixed value for the chemical concentration in that food. For packaging migrating chemicals this single value can represent:

$>$ the value assuming that all amounts of the substance initially present in the packaging material, migrates into the food product (Leber, 2001),

$>$ the value corresponding to the specific migration limit (legal limit),

$>$ an average migration value obtained experimentally, i.e. a value obtained by testing with food simulant packages not previously used (Brede \& Skjevrak, 2004; DFVF, 2004; Fankhauser-Noti \& Grob, 2004; Grob et al., 2007; Simoneau et al., 1999).

Many of the assessments reported in the literature are, however, surveys where samples (in most cases less than 50) were collected from the market and analysed to determine the concentration of the target substance (Bradley et al., 2005, 2004; Freire et al., 2006; FSA, 2003; Nestmann et al., 2005; Thomson \& Grounds, 2005). The concentration value is then combined with data for food consumption.

Fig. 1 shows a strategy proposed by the UK Food Standards Agency to calculate exposure levels, which follows a progressive refinement approach of point-estimates (FSA, 2003).

Inherent to the point estimate approach are the assumptions that all individuals consume the specified food(s) at the same level, that the food chemical is always present in the food(s) and that it is always present at an average or high level. This approach does not provide an insight into the range of possible exposures that may occur within a population, or the main factors influencing the presence of the putative hazard in the food (Kroes et al., 2002).

Presently in the EU, the specific migration limits are set assuming that, for the substance under consideration:

- every person eats $1 \mathrm{~kg} /$ day, over a lifetime, packaged in the material that contains that substance;

- the food $(1 \mathrm{~kg})$ is in contact with $6 \mathrm{dm}^{2}$ of packaging material;

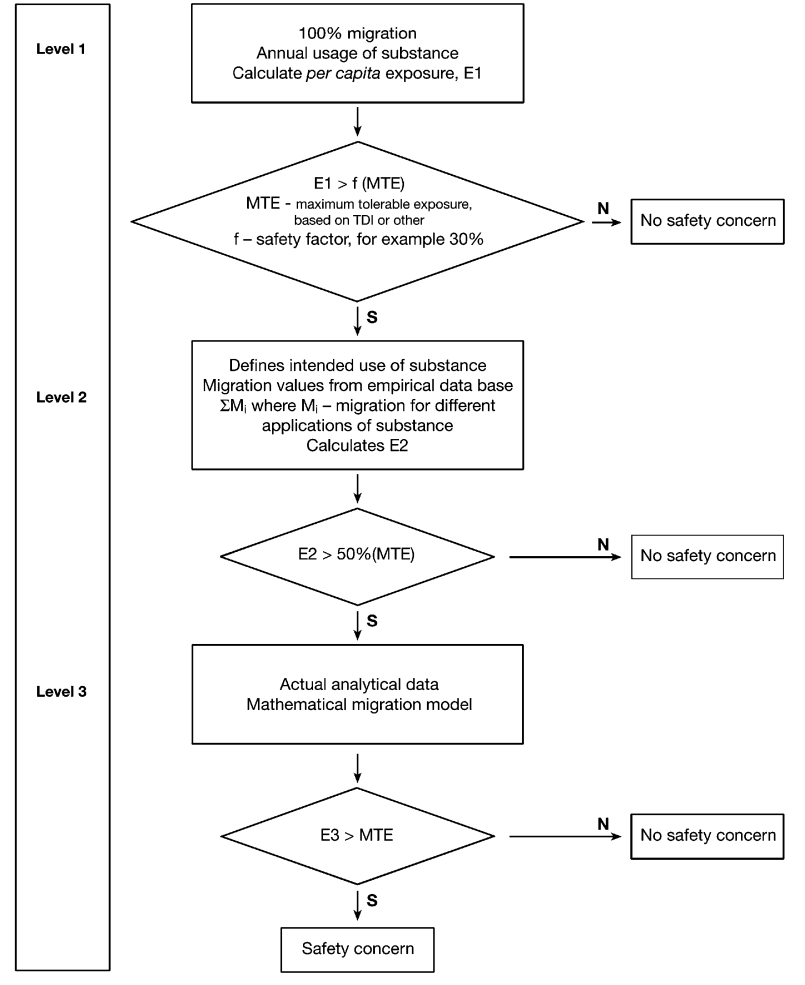

Fig. 1. Tiered approach proposed by FSA.

- average consumer body weight is $60 \mathrm{~kg}$;

- there is no other significant source of exposure.

The SML is set as the maximum value that yields an intake lower than the TDI or some other applicable safety criteria. This approach has value as a worst-case assumption and can be combined together with real, average migration data to point estimate the intake.

It is recognised that improvements are required and further information is needed to allow refinement of these estimates. It is argued that this model actually underestimates exposure in certain cases, e.g. high consumption of beverages, increased use of small sized packaging, special groups of consumers, children that eat more than adults when body weight is taken into account and possible exposure of the chemicals from other sources (NNT, 2003). On the other extreme, the model overestimates exposure to substances migrating into fatty food, since people do not or cannot eat more than $200 \mathrm{~g}$ of fat regularly every day and the actual exposure model assumes that every citizen consume $1 \mathrm{~kg}$ of food (including fatty foods) each day over a lifetime. To take this into account, a Fat Reduction Factor (FRF) is included in the 4th amendment to Directive $2002 / 72$. This factor will be used for the correction of the experimental migration value, before comparison with the specific migration limit on the European Directives.

Children represent a sub-group with specific consumption patterns. One example of this is that children drink more milk than adults and much of the milk is full fat, thus increasing the risk of a higher amount of fat soluble 
chemicals from the packaging migrating into the milk. Children also eat more fermented milk products than adults and most of these come in small packages aimed specifically at children. Thus, the ratio $1 \mathrm{~kg}$ of food contacting $6 \mathrm{dm}^{2}$ of packaging material for a $60 \mathrm{~kg}$ person does describe this special group of consumers very well (NNT, 2003). Packaging systems which comply with the SML may, however, cause the TDI to be exceeded for children (Duffy, Hearty, Flynn, McCarthy, \& Gibney, 2006; FSA, 2003).

Food consumption by infants and small children is much higher, on a body weight basis, than for the conventional adult model of $1 \mathrm{~kg}_{\text {food }} / 60 \mathrm{~kg}$ bw, as shown in Table 3 .

In the study presented by Duffy, Hearty, Flynn, et al. (2006), the amount of food consumed by Irish children aged 5-12 years is segregated according to the packaging type. They show that for this segment of population, the mean daily intake of packaged food is $1195 \mathrm{~g} /$ day corresponding to $39 \mathrm{~g} /$ day $/ \mathrm{kg} \mathrm{bw}$. Plastic packaging accounts for $83 \%$ of the food that is packaged and $66 \%$ of all food consumed. The mean daily fat intake is calculated as $63 \mathrm{~g} /$ day, milk being the largest contributor.

The assumption of individuals eating $1 \mathrm{~kg}$ /day in a cube of surface area $6 \mathrm{dm}^{2}$, packaged with the same material, has also been considered inappropriate for canned foods (Dionisi \& Oldring, 2002). Calculations of the contacting surface area of cans consumed (from the average can sizes) indicate that, on a per capita basis, the surface area of canned foodstuffs and canned beverages is about $1 \mathrm{dm}^{2}$, one sixth of the EU assumption. Therefore, any exposure resulting from consumption of canned food and beverage, where the migrants are specific to can coatings, is significantly less than in current EU exposure assessments of migrants from can coatings (Dionisi \& Oldring, 2002). More recent data indicate ratios of surface area to weight ranging from 8 to $17 \mathrm{dm}^{2} / \mathrm{kg}$ for food cans, and ranging from 0.2 to $1.2 \mathrm{dm}^{2} / \mathrm{kg}$ for metal closures (Oldring, Castle, Hart, \& Holmes, 2006).

ILSI derived an average value for food-contact area for all packaging, assuming an EU population of 350 million (excluding at that time Finland, Sweden and Austria), of $20.1 \mathrm{dm}^{2} /$ person/day and $12.4 \mathrm{dm}^{2} /$ person/day for plastics (62\% of all packaging by area). These figures are higher than the EU convention of assuming a $1 \mathrm{~kg} /$ person/day

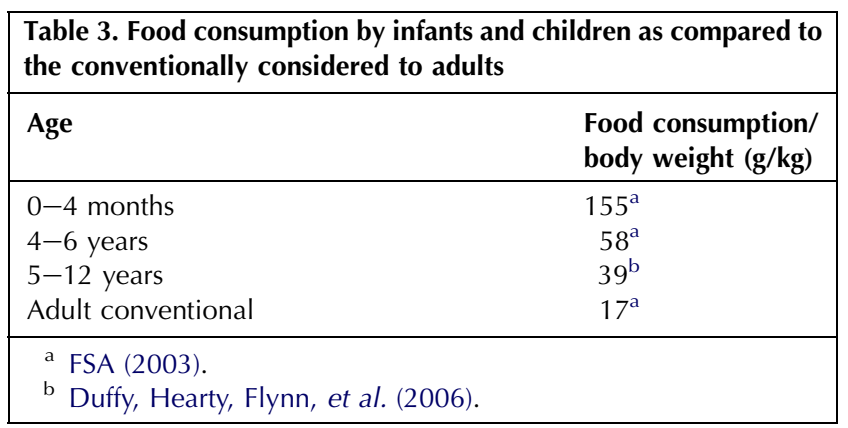

intake of food with a contact area of $6 \mathrm{dm}^{2} /$ person/day (ILSI, 1997). A conversion factor of $20 \mathrm{dm}^{2} / \mathrm{kg}$ is proposed by Grob et al. (2007).

The official agencies of the US follow a more refined first-step approach when compared to that applied in the EU. The FDA defines a consumption factor (CF) that describes the fraction of the daily diet expected to contact specific packaging materials and a food-type distribution factor (FT) that accounts for the variable nature of food contacting each type of packaging material (CFSAN, 2002). This factor reflects the fraction of all food contacting each material that is aqueous, acidic, alcoholic and fatty. FDA default food-contact ratio is $10 \mathrm{~g}$ food/in ${ }^{2}$ packaging that is not much different from the European default value. The calculation of the value of migration scaled according to the actual fraction of food of each type is given by:

$$
\begin{aligned}
M\left(\mathrm{mg} / \mathrm{kg}_{\text {food }}\right)= & \mathrm{FT}_{\text {aqueous and acidic }} M_{10 \% \text { ethanol }} \\
& +\mathrm{FT}_{\text {alcohol }} M_{50 \% \text { ethanol }}+\mathrm{FT}_{\text {fatty }} M_{\text {fatty }}
\end{aligned}
$$

where $M$ is the total migration and $M_{i}$ refers to the migration into the food simulant $i\left(\mathrm{mg} / \mathrm{kg}_{\text {food simulant }}\right)$, and the estimated daily intake (EDI) of the chemical is given by:

$$
\begin{aligned}
\operatorname{EDI}(\mathrm{mg} / \text { person } / \text { day })= & M\left(\mathrm{mg} / \mathrm{kg}_{\text {food }}\right) \times \mathrm{CF} \\
& \times 3 \mathrm{~kg}_{\text {food }} / \text { person } / \text { day }
\end{aligned}
$$

This approach was followed to compare the worst-case daily intake of dehydroabietic and abietic acids with the TDI of rosin, to assess the exposure to bisphenol A from baby milk bottles and to assess the exposure to mineral hydrocarbons from various sources (Heimbach et al., 2002; Wong et al., 2005).

Duffy, Hearty, Flynn, et al. (2006) also estimates the amount of food consumed (by Irish children aged 5-12 years) per type of EU food category corresponding to different migration simulants (Table 4). These data can be the basis for point-estimates of exposure using an approach similar to that of the FDA.

A different approach may be followed using the consumption factor, $\mathrm{CF}$, and instead of using the values for migration obtained experimentally for each simulant and contact conditions, using migration values estimated with mathematical models based on diffusion theory (Lickly et al., 1995).

\begin{tabular}{|llr|}
\hline \multicolumn{3}{|l|}{$\begin{array}{l}\text { Table 4. Intake of packaged food of different EU classes of foods by } \\
\text { young children (Duffy, Hearty, Flynn, et al., 2006) }\end{array}$} \\
\hline Intake (g/day) & Mean & SD \\
\hline Aqueous & 312 & 196 \\
Acidic & 374 & 206 \\
Fatty & 177 & 69 \\
Dry & 333 & 119 \\
\hline
\end{tabular}




\section{Probabilistic approach}

In contrast to the deterministic models for exposure that use a single estimate of each variable, probabilistic models take account every possible value that each variable can take and weigh each possible scenario based on the probability of its occurrence. This approach ensures that any variability and/or uncertainty in variables are reflected in the model output. Variability (true heterogeneity) refers to temporal, spatial or interindividual differences in the value of an input. Uncertainty (lack of knowledge) may be considered a measure of the incompleteness of knowledge or information about an unknown quantity whose true value could be established if a perfect measuring device were available. Random and systematic errors are sources of uncertainty (Cullen \& Frey, 1999).

Food consumption data have intrinsic uncertainty and variability. The observed values differ from the true value by systematic errors or bias (which occurs, generally, in the measurements of all measured subjects), and nonsystematic errors that vary unpredictably from subject to subject within the population under study (Hart et al., 2003; Lambe, 2002). Migration data are also subject to variability due to heterogeneity in the packaging system and in the composition and structure of the food product, and to uncertainty regarding, for example, the temperature along the distribution chain. At a laboratory scale, variability in migration value determination is also unavoidable, even when standardised procedures are used.

Both variability and uncertainty may be quantified using probability distributions. A very important part of any probabilistic exposure assessment of food chemicals is the selection of probability distributions for the uncertain input variables (Gilsenan, Lambe, \& Gibney, 2003; Lambe, 2002). A first step is the probability plot that can give an idea of the overall shape of the distribution. Some characteristics of the variable are useful for identifying classes of distributions (Parmar, Miller, \& Burt, 1997). Such characteristics include whether the variable is continuous or discrete, which are the limits of the values, the symmetry of the values and the range of values of most concern. Depending on the objective or purpose of the study, it must be defined whether the distributions of food consumption should reflect the distribution for the total population or only for consumers genuinely exposed to the hazard in question. In addition, it is very often required to decide what to do with migration data sets in which many results are reported as non-detected values, due to limits in the measurement. After selecting the class of distribution, the parameters of this distribution are estimated and the goodness-of-fit is evaluated, usually through statistical tests such as Chi-square, Kolmogorov-Smirnov or Anderson-Darling tests (Cullen \& Frey, 1999). Body weight, for example, is often described by a normal or lognormal distribution, while triangular distributions have been used to represent uncertainties affecting parameters estimated by expert judgement, for example, the market share for different types of packaging for the same product (Oldring et al.,
2006). The lognormal distribution is often used to represent food consumption data (Gilsenan et al., 2003). The initial concentration of the migrant in the packaging materials is assumed to be normally distributed and the diffusion coefficient is assumed to be log-normally distributed (Vitrac, Challe, Leblanc, \& Feigenbaum, submitted for publication).

A stochastic approach has been considered promising because it allows much more realistic estimates of exposure than single worst-case estimates (Petersen, 2000). This approach makes it possible to assess exposure for both average and high consumption, and to take into account the exposure to a combination of substances from different packaging and present in different food products (Vitrac \& Hayert, 2005).

The probabilistic approach has been followed for assessments of several food additives and contaminants. These include sweeteners (Arcella, Soggiu, \& Leclercq, 2003), pesticides (Boon, van der Voet, \& van Klaveren, 2003; López et al., 2003), flavouring substances (Lambe, Cadby, \& Gibney, 2002), vitamins (Rubingh, Kruizinga, Hulshof, \& Brussaard, 2003) and dioxin-like substances (Vrijens et al., 2002). Gibney and van der Voet (2003) present the conceptual model for probabilistic modelling of the intake of food chemicals and nutrients, used in the Monte Carlo European project. These authors also present the computational system developed in the project and made available as a web-based application (McNamara, Naddy, Rohan, \& Sexton, 2003).

More recently, probabilistic modelling has also been employed to assess the exposure to chemicals with their origins in packaging materials. The model developed by the CSL (Central Science Laboratory, UK) was applied to estimate the short-term exposure of UK consumers to residual bisphenol-A-diglycidyl-ether (BADGE) from can coatings of canned foods (Holmes et al., 2005; Oldring et al., 2006), to di-2-ethylhexyl-adipate (DEHA) and to styrene (Holmes et al., 2005) from several packaging systems. The model quantifies variability and uncertainty and uses a two-dimensional MC simulation which enables the separation of the influence of variability and uncertainty in the outputs (Fig. 2). The model is supported by UK consumption data from surveys and quantifies variability by estimating exposure for each population member using concentrations sampled from distributions based on measurements in real foods or food simulants (inner loop). Uncertainty is quantified in an outer loop, by repeating the inner loop with different assumptions about model inputs that are uncertain (consumption and concentration measurements, sampling, extrapolation of migration data from simulants to real foods and the proportion of food packaged).

This model was applied to any generalised migrant from coated, light metal cans, using different scenarios for migration data obtained with food simulants. The model was used to evaluate exposure for a given level of migration, and conversely, the level of migration that could be tolerated whilst keeping a target threshold exposure level (Castle, Hart, Holmes, \& Oldring, 2006). 


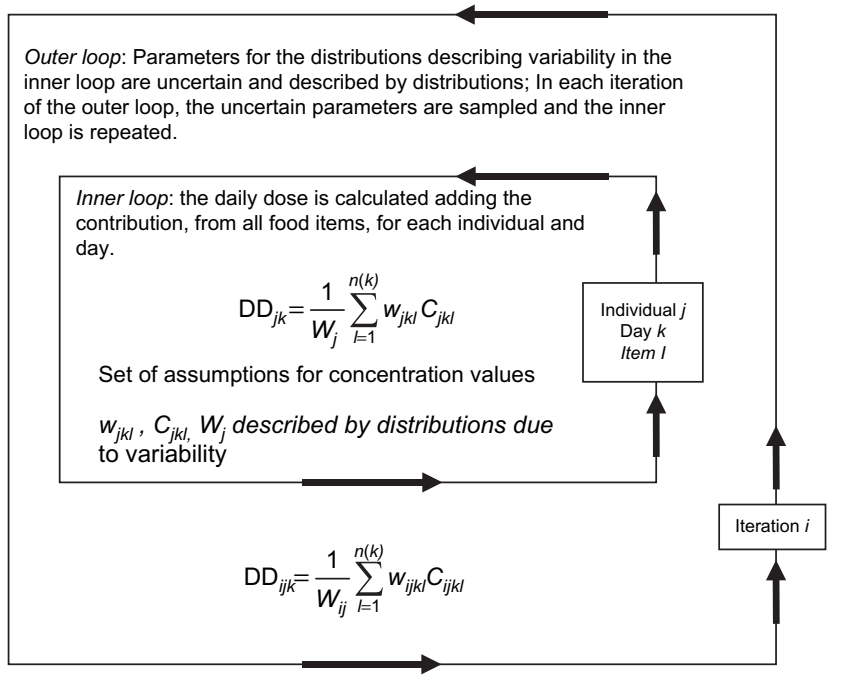

Fig. 2. Representation of the CSL model $\left(D_{j k}\right.$ is the daily dose for individual $j$ on day $k, W_{j}$ is the body weight of individual $j, w_{j k l}$ is the amount of item / eaten by $j$ on day $k, C_{j k l}$ is the concentration of the substance in item / eaten by $j$ on day $k$ ).

Unlike empirical methods based on Monte Carlo simulation, probabilistic modelling using consumption data and physical models to describe concentration of contaminants is an approach that does not depend on the availability of contamination data (Vitrac \& Hayert, 2005). The migration model is described by transport and mass balance equations depending on different parameters and variables. If each parameter or variable is replaced by a distribution of values, the result is a distribution of contamination values accounting for variability and uncertainty. The distribution of the concentration in food is derived from a stochastic resolution of dimensionless transport equations accounting for the physical properties of the food product, of the packaging material, and of possible migrants. Each parameter is decomposed into a product of a scale factor and a dimensionless random contribution with known distributions (Vitrac \& Hayert, 2005). This approach was followed by Vitrac et al. (submitted for publication) and Vitrac and Leblanc (in press) for exposure assessment of French consumers to styrene and to BHT antioxidant. They consider the probability density function of the concentration of migrating substances in foods (chemical contamination) in relation to the physical quantities that control the migration process, such as diffusion and packaging geometry, and to the initial concentration of the migrant in the packaging material. Distributions of storage times at the household scale may drastically modify the range of the contamination of packaged food products. This probabilistic approach allows for analysing the correlation between consumption patterns and storage times, and consequently between consumption and contamination, and for identification of household practices that might increase the exposure to migrants for certain consumption rate (Vitrac \& Leblanc, in press).

\section{Conclusions}

Packaging materials and systems for foods contain many substances which can migrate into the food during processing or storage. Increasingly, these substances are becoming subject to control and regulation. The major concern regarding safety of food-contact materials is that the effects of prolonged exposure in humans are still very poorly known. Risks, which are uncertain and unknown in their nature and extent, are known to be those which generate the greatest concern, quite independent of the actual risk they eventually prove to represent.

Some compounds can be present in foodstuff even though their introduction could not reasonably be expected from normal practices and procedures. Such contaminants might be degradation products of allowed or inoffensive molecules, impurities or unknowingly the result of "bad practices". Examples of this type of contamination might be ITX from printing inks or phthalates from corks. Such cases present particular problems as: (i) often no agreed screening methodologies exist (or they are not applied to the foodstuff as they are not expected to be present) and (ii) there is a lack of toxicological data which could support the definition of a safety objective. Additionally, in many cases the packaging producers do not have full information on the additives that their suppliers use in the raw material, thus making compliance assessment, highly complex and expensive.

A number of approaches can be employed for the assessment of consumer exposure to chemical contaminants from packaging, some being more suited than others to particular objectives and conditions of data quality and quantity. Probabilistic modelling has proved to be an excellent tool for the exposure assessment of food additives, pesticides and other contaminants. Its application in exposure assessment of substances migrating from packaging is regarded as of increasing interest. Conservative assumptions, related to point estimates, are a useful tool for screening phases, but increase the risk of rejecting a safe system. The main restriction for the application of full probabilistic approaches is the lack of food consumption data and its correspondence with packaging formulations and uses (Vitrac et al., submitted for publication). Some databases on food packaging are available but are useful mainly as resources of general information, since data are not routinely recorded with the required detail for refined exposure assessments (Duffy, Hearty, Gilsenan, et al., 2006). It is recognized that adequate guidelines for data collecting must be drawn up and that procedures must be harmonized. For example, the 7-day food diary is considered the "gold standard" method for the collection of information on the consumption of packaged foods (Duffy, Hearty, Gilsenan, et al., 2006). It should be noted, however, that this approach requires considerable effort which may not always be justified.

Predictive mathematical models seem to be a promising tool to provide migrant concentration data, for different packaging formats and food products. These models can be used, with good quality data on packaging usage, as 
inputs into probabilistic models. In this type of approach, each predictive model would only supply contamination data for a particular substance from a particular source. A complete exposure assessment would require predictive models for each different source of contaminant in each source of exposure or point data for some sources and model derived data for others. Nevertheless, this approach is very useful when a new substance or substances for particular applications are under assessment and the consequence of this on the global exposure is of particular interest.

The exercise of evaluating consumer exposure to package derived substances is, by its nature, increasingly difficult, time consuming and costly. At the same time it should not be forgotten that packaging is itself very often a major, positive, contributor to food safety. Therefore, exposure assessments of contaminants from packaging materials and the effort required in their execution should be considered in the perspective of a risk-benefit analysis of the system. That is, also considering how important the substance is in the performance of the system in terms of prevention of food spoilage or deterioration, what alternatives are available, etc.

The collection of updated and more complete data on packaging usage would enable the refinement and possible correction of current EU assumptions. The development of a framework, bringing together consumption and food-type distribution factors, at European level, would permit the adoption of an approach somewhere between the simplified point estimates and the elaborated probabilistic approaches based on data collected at consumer level. Such an approach, whilst possessing many of the virtues of the FDA model, would be better adapted to European consumer patterns.

\section{References}

Anderson, W. A. C., Castle, L., Scotter, M. J., Massey, R. C., \& Springall, C. (2001). A biomarker approach to measuring human dietary exposure to certain phthalate diesters. Food Additives and Contaminants, 18(12), 1068-1074.

Arcella, D., Soggiu, M. E., \& Leclercq, C. (2003). Probabilistic modelling human exposure to intense sweeteners in Italian teenagers: validation and sensitivity analysis of a probabilistic model including indicators of market share and brand loyalty. Food Additives and Contaminants, 20(Suppl. 1), S73-S86.

Arvanitoyannis, I. S., \& Bosnea, L. (2004). Migration of substances from food packaging materials to foods. Critical Reviews in Food Science and Nutrition, 44, 63-76.

Aurela, B., Kulmala, H., \& Soderhjelm, L. (1999). Phthalates in paper and board packaging and their migration into Tenax and sugar. Food Additives and Contaminants, 16(12), 571-577.

Binderup, M.-L., Pedersen, G. A., Vinggaard, A. M., Rasmussen, E. S., Rosenquist, H., \& Cederberg, T. (2002). Toxicity testing and chemical analysis of recycled fibre-based paper for food contact. Food Additives and Contaminants, 19(Suppl.), 13-28.

Boon, P. E., van der Voet, H., \& van Klaveren, J. D. (2003). Validation of a probabilistic model of dietary exposure to selected pesticides in Dutch infants. Food Additives and Contaminants, 20(Suppl. 1), S36-S49.

Bradley, E. L., Boughtflower, T. L., Smith, L., Speck, D. R., \& Castle, L. (2005). Survey of the migration of melamine and formaldehyde from melamine food contact articles available on the UK market. Food Additives and Contaminants, 22(6), 597-606.

Bradley, E. L., Speck, D. R., Read, W. A., \& Castle, L. (2004). Method of test and survey of caprolactam migration into foods packaged in nylon-6. Food Additives and Contaminants, 21(12), 1179-1185.

Brede, C., \& Skjevrak, I. (2004). Migration of aniline from polyamide cooking utensils into food simulants. Food Additives and Contaminants, 21(11), 1115-1124.

Castle, L. (2003). Contaminants from food packaging. Presentation in CSL/JIFSAN Joint Symposium Food Safety and Nutrition: Risks Analysis, June 11-13, Maryland.

Castle, L., Hart, A., Holmes, M. J., \& Oldring, P. K. T. (2006). Approach to stochastic modelling of consumer exposure for any substance from canned foods using simulant migration data. Food Additives and Contaminants, 23(5), 528-538.

Castle, L., Kelly, M., \& Gilbert, J. (1993). Migration of mineral hydrocarbons into foods. 3. Cheese coatings and temporary casings for skinless sausages. Food Additives and Contaminants, 10(2), 175-184.

CFSAN. (2002). Guidance for industry preparation of food contact notifications and food additive petitions for food contact substances: Chemistry recommendations. Maryland: U.S. Department of Health and Human Services, Food and Drug Administration, Center for Food Safety and Applied Nutrition.

CoE. (2002). Resolution AP (2002)1 on paper and board materials and articles intended to come in contact with foodstuffs. Council of Europe, Committee of Ministers on 18 September 2002.

Cullen, A. C., \& Frey, H. C. (1999). Probabilistic techniques in exposure assessment: A handbook for dealing with variability and uncertainty in models and inputs. New York: Society of Risk Analysis.

DFVF. (2004). An acute case of primary aromatic amines migrating from cooking utensils. Memorandum for the Danish veterinary and Food Administration, Danish Institute for Food and Veterinary Research.

Dionisi, G., \& Oldring, P. K. T. (2002). Estimates of per capita exposure to substances migrating from canned foods and beverages. Food Additives and Contaminants, 19(9), 891-903.

Duffy, E., Hearty, A. P., Flynn, A., McCarthy, S., \& Gibney, M. J. (2006). Estimation of exposure to food packaging materials. 2: Patterns of intakes of packaged food in Irish Children aged 5-12 years. Food Additives and Contaminants, 23(7), 715-725.

Duffy, E., Hearty, A. P., Gilsenan, M. B., \& Gibney, M. J. (2006). Estimation of exposure to food packaging materials. 1: Development of a food-packaging data base. Food Additives and Contaminants, 23(6), 623-633.

EC. (no date). Report on dietary food additive intake in the European Union. Health \& Consumer Protection DG. Available from http:// ec.europa.eu/food/food/chemicalsafety/additives/index_en.htm.

EFSA. (2004). Statement of the Scientific AFC Panel on the re-classification of some phthalates for consistency with new SCF guidelines for food contact materials. Parma: European Food Safety Authority.

EFSA. (2005). Food contact materials note for guidance. Parma: European Food Safety Authority.

Escabasse, J. Y., \& Ottenio, D. (2002). Food-contact paper and board based on recycled fibres: regulatory aspects - new rules and guidelines. Food Additives and Contaminants, 19(Suppl.), 79-92.

Fankhauser-Noti, A., \& Grob, K. (2004). Migration of trimellitic acid from epoxy anhydride can coatings into foods. Food Additives and Contaminants, 21(7), 711-718.

Freire, M. T. A., Santana, I. A., \& Reyes, F. G. R. (2006). Plasticizers in Brasilian food-packaging materials acquired on the retail market. Food Additives and Contaminants, 23(1), 93-99.

FSA. (2002). Investigation of the significant factors in elemental migration from glass in contact with food. Final Report Project Code A03029. UK: Food Standards Agency. 
FSA. (2003). Approaches to assess risk and assign priorities to chemicals used to make food contact materials. Final Report Project Code A03023. UK: Food Standards Agency.

Gibney, M. J., \& van der Voet, H. (2003). Introduction to the Monte Carlo project and the approach to the validation of probabilistic models of dietary exposure to selected food chemicals. Food Additives and Contaminants, 20(Suppl. 1), S1-S7.

Gilsenan, M. B., Lambe, J., \& Gibney, M. J. (2003). Assessment of food intake input distributions for use in probabilistic exposure assessments of food additives. Food Additives and Contaminants, 20(11), 1023-1033.

Grob, K. (2002). Comprehensive analysis of migrates from foodpackaging materials: a challenge. Food Additives and Contaminants, 19(Suppl.), 185-191.

Grob, K., Pfenninger, S., Pohl, W., Laso, M., Imhof, D., \& Rieger, K. (2007) European legal limits for migration from food packaging materials: 1 Food should prevail over simulants; 2 . More realistic conversion from concentrations to limits per surface area. PVC cling films in contact with cheese as an example. Food Control, 18(3), 201-210.

Hart, A., Smith, G. C., Macarthur, R., \& Rose, M. (2003). Application of uncertainty analysis in assessing dietary exposure. Toxicology Letters, 140-141, 437-442.

Heimbach, J. T., Bodor, A. R., Douglass, J. S., Barraj, L. M., Cohen, S. C., Biles, R. W., et al. (2002). Dietary exposures to mineral hydrocarbons from food-use applications in the United States. Food Chemical Toxicology, 40, 555-571.

Holmes, M. J., Hart, A., Northing, P., Oldring, P. K. T., \& Castle, L. (2005). Dietary exposure to chemical migrants from food contact materials: a probabilistic approach. Food Additives and Contaminants, 22(10), 907-919.

ILSI. (1997). Workshop report - food packaging - food consumption factors. Packaging Technology and Science, 10, 281-289.

ILSI. (2002). Report series - Exposure from food contact materials Summary report of a workshop held in October 2001, International Life Sciences Institute Europe.

Jickells, S. M., Poulin, J., Mountfort, K. A.., \& Fernandez-Ocaña, M. (2005). Migration of contaminants by gas phase transfer from carton board and corrugated board box secondary packaging into foods. Food Additives and Contaminants, 22(8), 768-782.

Kroes, R., Muller, D., Lambe, J., Lowik, M. R. H., Klaveren, J., Kleiner, J., et al. (2002). Assessment of intake from the diet. Food and Chemical Toxicology, 40, 327-385.

Lambe, J. (2002). The use of food consumption data in assessments of exposure to food chemicals including the application of probabilistic modelling, Proceedings of the Symposium "Nutritional aspects of food safety". Nutrition Society, 61, 11-18.

Lambe, J., Cadby, P., \& Gibney, M. (2002). Comparison of stochastic modelling to the intakes of intentionally added flavouring substances with theoretical added maximum daily intakes (TAMDI) and maximized survey-derived daily intakes (MSDI). Food Additives and Contaminants, 19(1), 2-14

Latini, G. (2005). Monitoring phthalate exposure in humans. Clinica Chimica Acta, 361, 20-29.

Leber, A. P. (2001). Human exposures to monomers resulting from consumer contact with polymers. Chemico-Biological Interactions, 135-136, 215-220.

Leblanc, J. C., Guérin, T., Noel, L., Calamassi-Tran, G., Volatier, J. L., \& Verger, P. (2005). Dietary exposure estimates of 18 elements from the 1 st French total diet study. Food Additives and Contaminants, 22(7), 624-641.

Leclercq, C., Arcella, D., Armentia, A., Boon, P. E., Kruizinga, A. G., Gilsenan, M. B., et al. (2003). Development of databases for use in validation studies of probabilistic models of dietary exposure to food chemicals and nutrients. Food Additives and Contaminants, 20(Suppl. 1), S27-S35.

Lickly, T. D., Breder, C. V., \& Rainey, M. L. (1995). A model for estimating the daily dietary intake of a substance from food-contact articles: styrene from polystyrene food-contact polymers. Regulatory Toxicology and Pharmacology, 21, 406-417.

López, A., Rueda, C., Armentia, A., Rodríguez, M., Cuervo, L., \& Ocio, J. A. (2003). Validation and sensitivity analysis of a probabilistic model of dietary exposure assessment to pesticide residues with a Basque Country duplicate diet study. Food Additives and Contaminants, 20(Suppl. 1), S87-S101.

Luetzow, M. (2003). Harmonization of exposure assessment for food chemicals: the international perspective. Toxicology Letters, 140-141, 419-425.

MAFF. (2003). Mineral hydrocarbons in food contact materials. Final Report 34/03. UK: Ministry of Agriculture Fisheries and Food.

McNamara, C., Naddy, B., Rohan, D., \& Sexton, J. (2003). Design, development and validation of software for modelling dietary exposure to food chemicals and nutrients. Food Additives and Contaminants, 20(Suppl. 1), S8-S26.

Munro, I. C., Hlywka, J. J., \& Kennepohl, E. M. (2002). Risk assessment of packaging materials. Food Additives and Contaminants, 19(Suppl.), 3-12.

Mutsuga, M., Tojima, T., Kawamura, Y., \& Tanamoto, K. (2005). Survey of formaldehyde, acetaldehyde and oligomers in polyethylene terephthalate food-packaging materials. Food Additives and Contaminants, 23(2), 212-218.

Nestmann, E. R., Lynch, B. S., Musa-Veloso, K., Goodfellow, G. H., Cheng, E., Haighton, L. A., et al. (2005). Safety assessment and riskbenefit analysis of the use of azodicarbonamide in baby food jar closure technology: putting trace levels of semicarbazide exposure into perspective - a review. Food Additives and Contaminants, 22(9), 875-891.

NNT. (2003). Food reduction/consumption factors: an acceptable new element in the exposure assessment of substances from food contact materials? In Nordic Workshop, Joint Nordic Working Group on Food Toxicology, Copenhagen, November 2002.

Oldring, P. K. T., Castle, L., Hart, A., \& Holmes, M. J. (2006). Migrants from food cans revisited - application of a stochastic model for a more realistic assessment of exposure to BADGE. Packaging Technology and Science, 19, 121-137.

Parmar, B., Miller, P. F., \& Burt, R. (1997). Stepwise approaches for estimating the intakes of chemicals in food. Regulatory Toxicology and Pharmacology, 26, 44-51.

Petersen, B. J. (2000). Probabilistic modelling: theory and practice. Food Additives and Contaminants, 17(7), 591-599.

Rees, N. M. A., \& Tennant, D. R. (1993). Estimating consumer intakes of food chemical contaminants. In D. H. Watson (Ed.), Safety of chemicals in food: Chemical contaminants (pp. 175-181). Chichester: Ellis Horwood.

Rubingh, C. M., Kruizinga, A. G., Hulshof, K. F. A. M., \& Brussaard, J. H. (2003). Validation and sensitivity analysis of probabilistic models of dietary exposure to micronutrients: an example based on vitamin B6. Food Additives and Contaminants, 20(Suppl. 1), S50-S60

Simoneau, C., Theobald, A., Wiltschko, D., \& Anklam, E. (1999). Estimation of intake of BADGE from canned fish consumption in Europe and migration survey. Food Additives and Contaminants, 16(11), 457-463.

Skjevrak, I., Bred, C., Steffensen, I.-L., Mikalsen, A., Alexander, J., Fjeldal, P., et al. (2005). Non-targeted multi-component analytical surveillance of plastic food contact materials: identification of substances not included in EU positive lists and their risk assessment. Food Additives and Contaminants, 22(10), 1012-1022.

Sturaro, A., Rella, R., Parvoli, G., Ferrara, D., \& Tisato, F. (2006). Contamination of dry foods with trimethyldiphenylmethanes by migration from recycled paper and board packaging. Food Additives and Contaminants, 23(4), 431-436.

Tennant, D. R. (2004). The usage, occurrence and dietary intakes of white mineral oils and waxes in Europe. Food and Chemical Toxicology, 42, 481-492. 
Thomson, B. M., \& Grounds, P. R. (2005). Bisphenol A in canned foods in New Zealand: an exposure assessment. Food Additives and Contaminants, 22(1), 65-72.

Vitrac, O., Challe, B., Leblanc, J.-C., Feigenbaum, A. Risk contamination of packed food by substances migrating from a plastic layer in direct contact: a generic quantitative methodology at household scale. Food Additives and Contaminants, submitted for publication.

Vitrac, O., \& Hayert, M. (2005). Risk assessment of migration from packaging materials into foodstuffs. AlChE Journal, 51(4), 1080-1095.

Vitrac, O., \& Leblanc, J.-C. Consumer exposure to substances from plastic packaging materials. 1. Assessment of the contribution of styrene from yoghurt pots. Food Additives and Contaminants, in press.

Vose, D. (2000). Risk analysis: A quantitative guide. West Sussex: John Wiley and Sons Ltd.
Vrijens, B., Henauw, S., Dewettink, K., Talloen, W., Goyens, L., Backer, G., et al. (2002). Probabilistic intake assessment and body burden estimation of dioxin-like substances in background conditions and during a short food contamination episode. Food Additives and Contaminants, 19(7), 687-700.

WHO. (1997). Guidelines for predicting dietary intake of pesticide residues. Document WHO/FSF/FOS/97.7. Geneva: World Health Organization.

Wong, K. O., Leo, L. W., \& Seah, H. L. (2005). Dietary exposure assessment of infants to bisphenol A from the use of polycarbonate baby milk bottles. Food Additives and Contaminants, 22(3), 280288.

Ysart, G., Miller, P., Crews, H., Robb, P., Baxter, M., L'Argy, C., et al. (1999). Dietary exposure estimates of 30 elements from the UK total diet study. Food Additives and Contaminants, 16(9), 391-403. 